\title{
Highly Sensitive Optical Sensor for Selective Detection of Fluoride Level in Drinking Water: Methodology to Fabrication of Prototype Device
}

Arka Chatterjee ${ }^{1}$, Nivedita Pan ${ }^{1}$, Tuhin Kumar Maji ${ }^{1}$, Sheik Saleem Pasha ${ }^{2}$, Soumendra Singh $^{3}$, Saleh A. Ahmed ${ }^{4,5,6}$, Jalal T. Al-Thakafy ${ }^{4}$ and Samir Kumar Pal ${ }^{1, *}$

${ }^{1}$ Department of Chemical, Biological and Macromolecular Sciences, S. N. Bose National Centre for Basic Sciences,Block JD, Sector III, Salt Lake, Kolkata 700 106, India

${ }^{2}$ Analytical and Environmental Science Division and Centralized Instrument Facility, CSIRCentral Salt and Marine Chemicals Research Institute, Bhavnagar, Gujarat 364 002, India.

${ }^{3}$ Technical Research Centre, Department of Chemical, Biological and Macromolecular Sciences, S. N. Bose National Centre for Basic Sciences,Block JD, Sector III, Salt Lake,Kolkata 700 106, India

${ }^{4}$ Department of Chemistry, Faculty of Applied Science, Umm Al-Qura University, 21955 Makkah, Saudi Arabia

${ }^{5}$ Research laboratories unit, Faculty of Applied Science, Umm Al-Qura University, 21955 Makkah, Saudi Arabia

${ }^{6}$ Chemistry Department, Faculty of Science, Assiut University, 71516 Assiut, Egypt

*Corresponding Author

E-mail: skpal@bose.res.in

Telephone: +910332335 5706-08

Fax: +9103323353477 


\begin{abstract}
Excess consumption of fluoride through drinking water and its detrimental effects on human health have been a serious global concern. Therefore, frequent monitoring as well as quantitative determination of fluoride ion $\left(\mathrm{F}^{-}\right)$concentration in aqueous media is of vital importance. Herein, we have developed a facile and highly sensitive spectroscopic technique for selective detection of $\mathrm{F}^{-}$in aqueous media using aluminium phthalocyanine chloride (AIPc-Cl) as a sensor. The absorbance as well as steady-state fluorescence intensity of AIPc-Cl has been found to decrease in presence of $\mathrm{F}^{-}$which has been used as a marker for the determination of fluoride ion concentration in water. The structural change in AlPc-Cl after addition of $\mathrm{F}^{-}$has been thoroughly studied by using ${ }^{19}$ F NMR (Nuclear Magnetic Resonance) spectroscopy. Our detailed steady-state as well as time-resolved fluorescence studies reveal that the quenching mechanism is static in nature due to ground state complexation in between $\mathrm{F}^{-}$and $\mathrm{AIPc}-\mathrm{Cl}$ molecules. The response of the sensor is found to be linear over the $F^{-}$concentration regime from 0 to 6 parts per million (ppm) with a detection limit of $0.05 \mathrm{ppm}$. Additionally, it shows an excellent selectivity as well as an insignificant change in sensitivity even in the presence of interfering iron and aluminium ions. Based on the detailed photophysical study, we have further developed a low cost and portable prototype device which shows an excellent sensitivity with the detection limit of $0.10 \mathrm{ppm}$. This prototype device has a high prospect for real-time monitoring of fluoride ion concentration especially in remote areas.
\end{abstract}

Keywords: Aggregation, Quenching, Sensor, Prototype device, Steady-state fluorescence. 


\section{Introduction:}

Over the past decades, a great effort has been devoted to the discovery of new analytical methods for the reliable and cost effective detection of various targeted species including cations and anions. ${ }^{1-3}$ Fluoride is one of such essential anions, which has drawn much attention due to its vital importance in various environmental and health-care issues. ${ }^{4,5} \mathrm{~F}^{-}$is naturally found in soil and ground water, but there are several industrial and agricultural activities which are responsible for large scale fluoride contamination in water. Low content of $\mathrm{F}^{-}$plays an important role in treating the osteoporosis and prevent the dental cavities. Therefore, it is authorized to be added into toothpastes, pharmaceutical agents, and even drinking water. According to the World Health Organization (WHO), maximum permissible limit of $\mathrm{F}^{-}$in drinking water is $1.5 \mathrm{mg} /$ litre (or $\left.1.5 \mathrm{ppm}\right) .{ }^{6,7}$ However, a higher concentration of $\mathrm{F}^{-}$causes several health problems such as severe gastroenteritis, salivation, anorexia, muscle weakness, stiffness, restlessness, sweating, dyspnoea, ventricular abnormalities and tachycardia. ${ }^{8-10}$ Higher exposure of $\mathrm{F}^{-}$is also considered to be a major cause for neurotoxicity which results in lower IQ (intelligent quotient) in a child. ${ }^{11}$ Additionally, excess consumption of $\mathrm{F}^{-}$through drinking water causes dental and skeletal fluorosis which are considered to be endemic in at least 25 countries in all the continents including Africa, Europe, Asia, North and South America. ${ }^{8}$ Therefore, the detection of fluoride ion concentration in drinking water as well as its quantitative measurement across a wide concentration range is of vital importance.

Amongst the other toxic anions, fluoride is considered to be particularly detrimental due to its small size, high charge density, strong basic property and capability of making H-bonding. This in turn makes its detection a tedious prospect. ${ }^{12}$ Till date, a great variety of methods have been employed for the precise determination of $\mathrm{F}^{-}$in water, such as ISE (Ion Selective Electrode), ${ }^{13}$ ion chromatography, ${ }^{14}$ HR-ICP-MS (High Resolution Inductively Coupled 
Plasma Mass Spectrometry), ${ }^{15}$ AAS (Atomic Absorption Spectroscopy), ${ }^{16}$ MAS (Molecular Absorption Spectroscopy) ${ }^{17}$ etc. However, most of these conventional methods are costly, time consuming and require sophisticated instruments and expert hands to process. On the other hand, spectroscopic techniques based on absorbance and fluorescence are not only cost effective, they are also known for their high sensitivity and easy operation. In this regard, many fluorescent probes for the detection of $\mathrm{F}^{-}$have been developed based on different mechanisms; such as supramolecular recognition, ${ }^{18}$ Lewis acid base interactions, ${ }^{19}$ hydrogen bonding ${ }^{20}$ and boron-fluoride interaction. ${ }^{20}$ Most of these sensing strategies are based on organic molecular probes which are not only expensive but also need multi-steps procedure for synthesis. In this context, development of a low cost and highly sensitive as well as selective optical sensor is extremely required for the detection of $\mathrm{F}^{-}$in drinking water.

Recently, phthalocyanine (Pc) and its different derivatives have achieved much attention due to their unique spectroscopic, photoelectric, catalytic and structural properties. ${ }^{21,22}$ Over the years, different Pcs have been used in the field of solar cell, ${ }^{23}$ environmental remediation, ${ }^{24}$ photodynamic cancer therapy, ${ }^{25}$ antimicrobial activity, ${ }^{26}$ gas sensor, ${ }^{27}$ and biosensor devices. $^{28}$ In particular, their low cost synthesis procedure and selective interaction with different species also make them a useful candidate in the field of sensing. The introduction of various metal ions into the Pc moiety or changing the peripheral substituents can significantly affect the optical properties which in turn lead to change of their sensing properties. Previously, several Pc derivatives have been synthesized for the selective detection of different species. Kaya et al., synthesized cobalt (II) phthalocyanines bearing fluorinated substituents for sensing ammonia vapour present in the air. ${ }^{29}$ Ceken et al., developed a novel manganese phthalocyanine complex for the detection of silver and mercury ions. ${ }^{30}$ Aluminium phthalocyanine chloride $(\mathrm{AlPc}-\mathrm{Cl})$ is one of such $\mathrm{Pc}$ derivatives 
which has been previously used in various applications such as photovoltaic, anticancer and antimicrobial photodynamic therapy. ${ }^{31,32}$ The higher solubility of this material in the organic solvent (e.g. dimethyl sulfoxide, ethanol etc.) makes it a useful candidate amongst the other Pc compounds. In the early ' 80 s, Kenney et al. first demonstrated that fluoride ion could efficiently replace the chlorine ion $\left(\mathrm{Cl}^{-}\right)$in $\mathrm{AlPc}-\mathrm{Cl}$ due to its high electronegativity than the later and in turn makes a polymer-like structure of AlPc-F. ${ }^{33}, 34$ Till date, this property of AlPc-Cl molecules has never been utilized for the sensing of $\mathrm{F}^{-}$in aqueous media. Additionally, in most of these reports, the transformation of AlPc-Cl to AlPc-F in the presence of $\mathrm{F}^{-}$has been confirmed on the basis of powder X-ray diffraction (XRD) measurements. Although, for sensing purposes, the occurrence of such substitution reaction in liquid phase is required to be confirmed. Therefore, detailed structural characterization by using ${ }^{19} \mathrm{~F}$ NMR spectroscopy is important which is hardly reported in the literatures. Additionally, interference of different metal ions such as iron and aluminium in the sensing of $\mathrm{F}^{-}$is sparsely highlighted in the contemporary literatures.

In the present work, we have demonstrated that AlPc-Cl molecules are highly sensitive as well as selective towards the $\mathrm{F}^{-}$ions and react very fast to form the chain-like structure of AlPc-F. Substitution of $\mathrm{Cl}^{-}$ions by $\mathrm{F}^{-}$and subsequent formation of AlPc-F have been confirmed by employing the ${ }^{19} \mathrm{~F}$ NMR spectroscopy. It has been observed that this substitution reaction further leads to the quenching in absorbance as well as steady state fluorescence intensity of the probe. By using the above mentioned property of AlPc-Cl molecules, we have developed a facile, highly sensitive, selective and cost effective method for the sensing of $\mathrm{F}^{-}$in aqueous media. Different spectroscopic techniques such as absorbance, steady-state fluorescence and picosecond time-resolved fluorescence spectroscopy have been employed to investigate the optical properties of $\mathrm{AlPc}-\mathrm{Cl}$ in the 
presence of $\mathrm{F}^{-}$. Moreover, the selectivity of the sensor in the presence of wide range of ions as well as interference of iron and aluminium ions in the sensing of $\mathrm{F}^{-}$has been thoroughly studied. In the present report, we have also developed a low cost, highly sensitive and portable prototype device for monitoring in field environmental fluoride pollution. The proposed device is expected to provide an inexpensive solution to the quantitative detection of fluoride ion concentration in the remote area where frequent monitoring of fluoride level is highly required.

\section{Experimental Section:}

\subsection{Chemicals:}

In the present study, all the chemicals were analytical in grade and used without further purification. Aluminium phthalocyanine chloride $\left(\mathrm{C}_{32} \mathrm{H}_{16} \mathrm{AlClN}_{8}\right)$, Sodium Fluoride $(\mathrm{NaF})$ and Methanol-d4 (Deuterated methanol) were purchased from Sigma-Aldrich. Ethanol was purchased from Merck. All the other salts containing cations and anions in the form of chloride and nitrate were purchased from Merck or Sigma-Aldrich. The stock solutions of all the salts were prepared in Millipore water (Millipore System, 18.2 MU cm).

\subsection{Preparation of Sensor:}

Certain amount of AlPc-Cl was added into anhydrous ethanol and stirred until fully dissolved to prepare $5.4 \mathrm{mM}$ stock solution. This solution was used as sensing material for the detection of fluoride in aqueous media. Here, 2 microlitre $(\mu \mathrm{L})$ of sensor solution $(5.4 \mathrm{mM}$ of AlPc-Cl in ethanol) was used for the sensing of fluoride ion concentration in aqueous media.

\subsection{Procedure of Fluoride ion $\left(\mathrm{F}^{-}\right)$Sensing Experiment:}

In order to replicate the real world samples, stock solution for different concentrations (e.g. 0 ppm, 0.2 ppm, 0.4ppm, 0.6 ppm, 0.8 ppm, 1.0 ppm, 1.5 ppm, 2.0 ppm, 2.5 ppm, 3.0 ppm, 4.0 ppm, $5.0 \mathrm{ppm}$ and $6.0 \mathrm{ppm}$ ) of fluoride were prepared by adding required amount of $\mathrm{NaF}$ in Millipore water. For the sensing purpose, firstly, $2 \mu \mathrm{L}$ of sensor was added into $2 \mathrm{~mL}$ of 
anhydrous ethanol, previously taken in a cuvette. Thereafter, $50 \mu \mathrm{L}$ of particular concentrated fluorinated water was added into the sensor solution. Finally, the absorbance and emission were taken in order to see the effect of certain $\mathrm{F}^{-}$concentration in the optical properties of the sensor. For each concentration of fluoride, a fresh stock of ethanol and sensor were used. ${ }^{35}$

\subsection{Characterization Methods:}

All the optical measurements were carried out at room temperature by using a quartz cuvette having $1 \mathrm{~cm}$ path length. The UV-Vis absorbance spectra were taken in JASCO spectrophotometer (V-750). The steady-state fluorescence spectra of the samples were recorded in JASCO spectrofluorometer (FP-8200) upon excitation at $633 \mathrm{~nm} .{ }^{19} \mathrm{~F}$ NMR spectra were recorded using a Bruker AX 500 spectrometer (500 MHz) NMR spectroscope. Time resolved fluorescence studies were performed in a picosecond resolved single photon counting setup (Edinburg instrument) having instrument response function (IRF) of 90 picoseconds upon excitation at $633 \mathrm{~nm}$. The details of nonlinear least square fitting procedure could be found in our earlier works. ${ }^{36}$ Here, all the measurements were carried out at room temperature $\left(27^{\circ} \mathrm{C}\right)$.

\section{Results and Discussion:}

Figure 1a represents the absorbance of $\mathrm{AlPc}-\mathrm{Cl}$ in ethanol medium. As shown in the figure, the absorption spectrum shows two major bands, cantered at 355 (soret band) and $672 \mathrm{~nm}(\mathrm{Q}$ band) respectively which are attributed to $\pi-\pi^{*}$ HOMO-LUMO transitions. These are also known as characteristic peaks of phthalocyanines in the monomeric state. ${ }^{37}$ Besides that, there are two other $\mathrm{Q}$ bands, positioned at $610 \mathrm{~nm}$ and $642 \mathrm{~nm}$, which are assigned to vibrational transitions. The molecular structure of $\mathrm{AlPc}-\mathrm{Cl}$ has been shown in the inset of the figure. The steady-state fluorescence spectrum of AlPc-Cl $\left(\lambda_{\mathrm{ex}}=633 \mathrm{~nm}\right)$ has been depicted in figure $1 \mathrm{~b}$. It shows an emission maximum at a wavelength of $682 \mathrm{~nm}$, originated due to the $\mathrm{S}_{1} \rightarrow \mathrm{S}_{0}$ transition. ${ }^{37}$ Whereas, two additional bands at 711 and $746 \mathrm{~nm}$, having lesser 
intensities are related to vibrational state transitions. The corresponding excitation spectrum $\left(\lambda_{\mathrm{em}}=682 \mathrm{~nm}\right)$ of AlPc-Cl has been shown in the inset of the figure which is found to be consistent with the absorbance spectrum.

The effect of fluoride ions on the optical properties of AlPc-Cl molecules has been represented in figure $2 \mathrm{a}-\mathrm{b}$ respectively. The interaction of $\mathrm{F}^{-}$with the sensor has been found to be very fast which reaches a steady condition within 30 seconds (Figure S1). Figure 2a shows the absorbance spectra of $\mathrm{AlPc}-\mathrm{Cl}$ in the absence and presence of $\mathrm{F}^{-}(1 \mathrm{ppm}$ and 2 ppm). It can be clearly observed that the addition of $\mathrm{F}^{-}$introduces two significant changes in the absorbance spectrum of AlPc-Cl. Firstly, there is a significant decrease in the monomeric peak at $672 \mathrm{~nm}$. Secondly, the absorbance peak at $642 \mathrm{~nm}$ is found to increase with increasing concentration of $\mathrm{F}^{-}$. There is also a slight decrease in the soret band at $355 \mathrm{~nm}$. However, in the present study, we have particularly concentrated at $672 \mathrm{~nm}$ peak due its significant change after addition of $\mathrm{F}^{-}$.

The effect of $\mathrm{F}^{-}$is also evident in the fluorescence spectra of $\mathrm{AlPc}-\mathrm{Cl}$. Figure $2 \mathrm{~b}$ shows the steady-state fluorescence spectra of $\mathrm{AlPc}-\mathrm{Cl}$ in the presence of $1 \mathrm{ppm}$ and $2 \mathrm{ppm}$ of $\mathrm{F}^{-}$. Fluorescence spectra in the absence of $\mathrm{F}^{-}$has also been shown in the figure for better comparison. It is evident from the figure that the peak intensity at $682 \mathrm{~nm}$ is significantly quenched accompanied with a blue shift after addition of $\mathrm{F}^{-}$. The intensities of the other two satellite peaks at $711 \mathrm{~nm}$ and 746 are also found to decrease with increasing concentration of $\mathrm{F}^{-}$. However, quenching of fluorescence intensity at $682 \mathrm{~nm}$ has been found to be notably higher. Therefore, we have mainly concentrated on the spectral changes of $682 \mathrm{~nm}$ peak for sensing purposes.

\subsection{Sensing Mechanism:}

On the basis of XRD measurements, Kenney and co-workers first reported that $\mathrm{F}^{-}$ion could substitute the $\mathrm{Cl}^{-}$in the AlPc-Cl and subsequently form AlPc-F. ${ }^{33,34}$ They further proposed 
that AlPc-F has a unique molecular arrangement where AlPc molecules are vertically aligned in a unique linear stack with the fluorine atoms equally spaced and interlinked between the AlPc fragments. Later, Djurado and other research groups also supported the highly ordered and polymer-like structure of AlPc-F. ${ }^{38}$ However, in all of these earlier reports, the structural characterizations have been performed on solid state samples. Although, for sensing application, confirmation of such substitution reaction in liquid medium is highly essential.

Therefore, in the present report, we have thoroughly studied the mechanism of substitution reaction by using ${ }^{19} \mathrm{~F}$ NMR spectroscopy in methanol- $\mathrm{d}_{4}$. Figure 3 a represents the ${ }^{19} \mathrm{~F}$ NMR spectra of AlPc-Cl, NaF and AlPc-F. As expected, AlPc-Cl does not show any signal in the ${ }^{19} \mathrm{~F}$ NMR spectrum. NaF, the exchangeable reagent with chloride in AlPc-Cl molecule shows a singlet signal with a typical upfield shift at $-152.39 \mathrm{ppm} .{ }^{39}$ The successful formation of AlPc-F has been confirmed by measuring the ${ }^{19} \mathrm{~F}$ NMR spectra, following the addition of fluorinating agent to AlPc-Cl. The ${ }^{19}$ F NMR spectra of AlPc-F revealed two minor signals at -134.81 and $-138.16 \mathrm{ppm}$ along with two main signals at -135.65 and $-138.98 \mathrm{ppm}$ respectively. These four signals are expected due to internal and terminal fluorine nuclei in the formed chain-like structure of AlPc-F. These predicable signals are also attributed to the formation of AlPc-F complex with the anisotropic effect of phthalocyanine and multilayer formation. The proposed molecular structure of AlPc-F has been shown in figure $3 \mathrm{~b}$. The strong shielding effect by approximately $16 \mathrm{ppm}$ of AlPc-F molecules due to the presence of fluorine nuclei in the shielding region also gives an excellent evidence for the interaction of AlPc-Cl with $\mathrm{F}^{-}$. Here, the shielding region originates due to the ring current effect of the circulating $\pi$ electrons of phthalocyanine molecules as well as multilayer formation. Additionally, the complete absence of the fluorine signal at $-152.39 \mathrm{ppm}$ in ${ }^{19} \mathrm{~F}$ NMR spectrum of AlPc-F also provides indisputable evidence for the complete exchange of chlorine atoms of AlPc-Cl by fluorine to form the chain-like structure of AlPc-F. Therefore, it 
is confirmed that the interaction of $\mathrm{AlPc}-\mathrm{Cl}$ molecules with $\mathrm{F}^{-}$and subsequent formation of AlPc-F is possible in the liquid phase. As the fluoride concentration increases; maximum number of AlPc-Cl molecules participates in the substitution reaction which eventually decreases the concentration of monomers by increasing the chain-like structure of AlPc-F. This structure of AlPc-F is similar to H-type aggregation. This face to face aggregation or $\mathrm{H}$ type aggregation is mainly responsible for the decrease in absorbance as well as fluorescence intensity. ${ }^{40}$

To investigate the details of quenching mechanism the Stern-Volmer plot is further used. ${ }^{41}$ The classical Stern-Volmer equation can be expressed as

$\frac{\mathrm{F}_{0}}{\mathrm{~F}}=1+\mathrm{K}_{\mathrm{sV}}[\mathrm{Q}]$

Where $F_{0}$ and $F$ are the steady state fluorescence intensity of the fluorophore in the absence and presence of quencher, $[\mathrm{Q}]$ respectively. $\mathrm{K}_{\mathrm{SV}}$ is the Stern-Volmer constant. ${ }^{41}$ Here, the quenching mechanism of $\mathrm{AlPc}-\mathrm{Cl}$ in the presence of $\mathrm{F}^{-}$can be either static or dynamic (collisional). In case of dynamic quenching, the relative change in the fluorescence and average lifetime are linearly dependent to the concentration of quencher. Moreover, it is an excited state process and can be defined by the equation; $\mathrm{F}_{0} / \mathrm{F}=\tau_{0} / \tau$. Where, $\tau_{0}$ and $\tau$ are average lifetime of the fluorophore (here $\mathrm{AlPc}-\mathrm{Cl}$ ) in the absence and presence of quencher (here $\mathrm{F}^{-}$) respectively. Whereas, in case of static quenching, only the fluorescence intensity decreases with increasing concentration of quencher but fluorescence lifetime of the fluorophore remains the same. ${ }^{42}$ As shown in figure $4 a$, the plot of $F_{0} / F$ versus (vs) $\left[\mathrm{F}^{-}\right]$yields a good agreement with a linear relationship $\left(\mathrm{R}^{2}=0.993\right)$. Whereas, the picosecond resolved fluorescence transients of AlPc-Cl (Figure S2) exhibits insignificant change with increasing concentration of $\mathrm{F}^{-}$. Therefore, $\tau_{0} / \tau$ remains almost constant. It confirms that the quenching mechanism is static in nature due to the ground state complexation in between $\mathrm{AlPc}-\mathrm{Cl}$ and 
fluoride ions which further forms non-emissive or very weakly emissive AlPc-F complex. The value of $\mathrm{K}_{\mathrm{SV}}$ is calculated to be $6.9 \times 10^{5} \mathrm{M}^{-1}$.

The stoichiometric ratio and association constant of the sensor with fluoride ions have been established by using Benesi-Hildebrand equation. Assuming 1:1 stoichiometry in between AlPc-Cl molecules and fluoride ions, the applicable equation is as follows. ${ }^{43}$

$\frac{1}{\mathrm{~F}_{0}-\mathrm{F}}=\frac{1}{\left(\mathrm{~F}_{0}-\mathrm{F}_{\infty}\right) \mathrm{K}\left[\mathrm{F}^{-}\right]}+\frac{1}{\mathrm{~F}_{0}-\mathrm{F}_{\infty}}$

Where, $\mathrm{F}_{\infty}$, and $\mathrm{F}$ are fluorescence intensities of $\mathrm{AlPc}-\mathrm{Cl}$ molecules with very large and intermediate concentrations of $\mathrm{F}^{-}$respectively. Whereas, $\mathrm{F}_{0}$ defines the fluorescence intensity of the sensor in the absence of $\mathrm{F}^{-}$and $\mathrm{K}$ signifies the association constant. As shown in figure $4 \mathrm{~b}$, the plot of $1 /\left(\mathrm{F}_{0}-\mathrm{F}\right)$ vs $1 /\left[\mathrm{F}^{-}\right]$yields an excellent linear relationship $\left(\mathrm{R}^{2}=0.992\right)$ confirming 1:1 complexation in between AlPc-Cl molecules and fluoride ions. Along with, the association constant $(\mathrm{K})$ is obtained to be $3.64 \times 10^{5} \mathrm{M}^{-1}$ which is close to the calculated SternVolmer constant $\left(\mathrm{K}_{\mathrm{SV}}\right)$. Therefore, it can be concluded that the static quenching mechanism due to the formation of non-emissive complex in between fluoride and dye molecules is responsible for the decrease of absorbance as well as fluorescence intensity. ${ }^{44}$

\subsection{Sensitivity studies:}

Therefore, using both the techniques; such as absorbance and fluorescence, the sensor could efficiently detect the fluoride level in water. Figure 5a shows the UV-Vis absorbance spectra of $\mathrm{AlPc}-\mathrm{Cl}$ with increasing concentration of $\mathrm{F}^{-}(0 \mathrm{ppm}$ to $6 \mathrm{ppm})$. It can be clearly observed that the monomeric peak at $672 \mathrm{~nm}$ decreases significantly with increasing concentration of $\mathrm{F}^{-}$. Also, there is a small blue shift in the absorbance peak at higher concentration of $\mathrm{F}^{-}$. The plot of relative (rel.) absorbance $\left(\mathrm{A}_{0} / \mathrm{A}\right)$ of the sensor (monitored at $672 \mathrm{~nm}$ ), in the presence of different concentrations of $\mathrm{F}^{-}(0-6 \mathrm{ppm})$ has been represented in figure $5 \mathrm{~b}$. The plot shows a good agreement with linear relationship $\left(\mathrm{R}^{2}=0.994\right)$ throughout the concentration range which further increases the feasibility of the sensor for practical applications. 
The effect of $\mathrm{F}^{-}$on the steady-state fluorescence property of AlPc-Cl has been further demonstrated in figure 3a. As shown in the figure, the fluorescence intensity of $\mathrm{AlPc}-\mathrm{Cl}$ decreases with increasing concentration of $\mathrm{F}^{-}$. Also, a slight blue shift in the emission occurs at higher $\left[\mathrm{F}^{-}\right]$. Here, it is important to mention that the absorbance as well as fluorescence spectrum of $\mathrm{AlPc}-\mathrm{Cl}$ shows insignificant change upon addition of $0 \mathrm{ppm} \mathrm{F}^{-}(50 \mu \mathrm{L}$ water without $\left.\mathrm{F}^{-}\right)$. The plot of relative fluorescence intensity $\left(\mathrm{F}_{0} / \mathrm{F}\right)$ versus $\left[\mathrm{F}^{-}\right]$has been shown in figure 5d. It can be observed that the sensor follows an excellent linear behaviour $\left(R^{2}=0.990\right)$ for $0 \mathrm{ppm}$ to $6 \mathrm{ppm}$ of fluoride concentration. The slope of the calibration curves obtained from the absorbance and fluorescence experiments are found to be $0.321 \mathrm{ppm}^{-1}$ and 0.421 $\mathrm{ppm}^{-1}$ respectively. Additionally, the values of limit of detection (LOD), calculated from absorbance as well as fluorescence studies are $0.06 \mathrm{ppm}$ and $0.05 \mathrm{ppm}$ respectively. The obtained LOD values are well below the recommended limit (1.5 ppm) proposed by WHO as well as comparably low with respect to the recently reported spectroscopy based sensors. ${ }^{12,45-}$ 47 The low detection limit and linear response of the sensor for a wide range of fluoride concentrations make it a promising candidate in the field of fluoride sensing.

\subsection{Selectivity of the Sensor towards $\mathrm{F}^{-}$:}

In order to use the sensor for the determination of $\mathrm{F}^{-}$in practical samples; it is very necessary to check the selectivity of the sensing material. Therefore, in the present report, we have thoroughly studied the interference of the sensor with a series of cations such as $\mathrm{Ca}^{2+}, \mathrm{Mg}^{2+}$, $\mathrm{Fe}^{3+}, \mathrm{Al}^{3+}, \mathrm{Ni}^{+}, \mathrm{Co}^{+}, \mathrm{Cr}^{3+}, \mathrm{Cr}^{6+}, \mathrm{As}^{3+}, \mathrm{Pb}^{2+}, \mathrm{Hg}^{2+}, \mathrm{Zn}^{2+}$ and anions such as $\mathrm{Cl}^{-}, \mathrm{Br}^{-}, \mathrm{I}^{-}, \mathrm{CO}_{3}{ }^{2-}$, $\mathrm{NO}_{3}{ }^{2-}, \mathrm{HPO}_{4}{ }^{2-}, \mathrm{OAc}^{-}, \mathrm{C}_{2} \mathrm{O}_{4}{ }^{2-}, \mathrm{OH}^{-}, \mathrm{SO}_{4}{ }^{2-}$. Figure 6a-b represent the normalised (nor.) absorbance values (at $672 \mathrm{~nm}$ ) of the sensor in the presence of different cations and anions respectively. Similarly, figure $6 \mathrm{c}$ and d represent the normalised fluorescence intensity values (at $682 \mathrm{~nm}$ ) of the sensor in the presence of different cations and anions respectively. Here, normalised absorbance (at $672 \mathrm{~nm}$ ) and fluorescence intensity (at $682 \mathrm{~nm}$ ) values of the 
sensor in the presence as well as absence of $\mathrm{F}^{-}$are also shown for better comparison. The concentration of every species has been set to $2 \mathrm{ppm}$. It is evident from the figures that the sensor shows an insignificant response to different species. Therefore, it can be concluded that our procedure could be potentially applied for the determination of $\mathrm{F}^{-}$content in the practical samples without any interference of other species.

\subsection{Interference of Iron and Aluminium ions in the Sensing of $\mathrm{F}^{-}$:}

Compared to the other anions, $\mathrm{F}^{-}$is reported to be more reactive due to its high electronegativity and smaller in size. Therefore, interference of other metal ions in the sensing of $\mathrm{F}^{-}$cannot be neglected. Amongst different metal ions, iron $\left(\mathrm{Fe}^{3+}\right)$ and aluminium $\left(\mathrm{Al}^{3+}\right)$ make stable as well as water soluble complex in the form of iron fluoride $\left(\mathrm{FeF}_{3}\right)$ and aluminium fluoride $\left(\mathrm{AlF}_{3}\right)$ respectively. Therefore, in the present report, we have thoroughly investigated the interference behaviour of $\mathrm{Fe}^{3+}$ and $\mathrm{Al}^{3+}$ in the sensing of fluoride in aqueous media. In real water, iron presents in a wide range of concentration; therefore the probability of interference is higher. The chronic toxicity level of iron in water is reported to be in the range of $10-20 \mathrm{ppm}^{48}$ On the other hand, at normal $\mathrm{pH}$, very less concentration $(\sim 0.05 \mathrm{ppm})$ of aluminium is present in water. Despite this fact, its reactivity with fluoride is reported to be very higher. According to the WHO guidelines, the maximum permissible limit of aluminium in drinking water is $0.2 \mathrm{ppm}^{49}$ The interference of 10 and $20 \mathrm{ppm}$ of iron in the rel. absorbance $\left(\mathrm{A}_{0} / \mathrm{A}\right)$ and $\mathrm{fl}$. Intensity $\left(\mathrm{F}_{0} / \mathrm{F}\right)$ vs $\left[\mathrm{F}^{-}\right]$plots have been represented in figure $7 \mathrm{a}-\mathrm{b}$ respectively. In presence of $10 \mathrm{ppm}$ iron, the slope of the calibration curve and LOD value calculated from the absorbance studies are $0.308 \mathrm{ppm}^{-1}$ and $0.063 \mathrm{ppm}$ respectively (fl. studies: slope $\left._{\mathrm{fl}}=0.405 \mathrm{ppm}^{-1}, \mathrm{LOD}_{\mathrm{fl}}=0.052 \mathrm{ppm}\right)$. Whereas, in case of $20 \mathrm{ppm}$ of iron the slope and LOD values are found to be $0.291 \mathrm{ppm}^{-1}$ and $0.066 \mathrm{ppm}$ respectively (fl. studies: slope $\left._{\mathrm{fl}}=0.403 \mathrm{ppm}^{-1}, \mathrm{LOD}_{\mathrm{fl}}=0.053 \mathrm{ppm}\right)$. It is clearly evident that there is no significant change (less than $10 \%$ ) in the sensitivity and detection limit of the sensor even at the chronic 
toxicity level of iron in water. The interference of $\mathrm{Al}^{3+}(0.2 \mathrm{ppm})$ in the sensing property of AlPc-Cl has been demonstrated in figure $7 \mathrm{c}-\mathrm{d}$ respectively. The calibration curves obtained from $\mathrm{A}_{0} / \mathrm{A}$ and $\mathrm{F}_{0} / \mathrm{F}$ vs $\left[\mathrm{F}^{-}\right]$(7c-d respectively) plots in the presence of $0.2 \mathrm{ppm} \mathrm{Al}^{3+}$ (slope $_{\text {abs. }}=0.306 \mathrm{ppm}^{-1}$, slope $\mathrm{fl} .=0.391 \mathrm{ppm}^{-1}$ ) show less than $5 \%$ deviation from the calibration curve without aluminium. Also, the LOD values obtained from the absorbance and fluorescence studies are found to be 0.064 and $0.054 \mathrm{ppm}$ respectively. It implies insignificant interference of $0.2 \mathrm{ppm} \mathrm{Al}^{3+}$ in the sensing of $\mathrm{F}^{-}$using our probe. However, at higher concentrations of $\mathrm{Fe}^{3+}(\sim 30 \mathrm{ppm})$ and $\mathrm{Al}^{3+}(\sim 5 \mathrm{ppm})$, the sensitivity of the sensor has been found to decrease significantly (Figure S3). The higher interference of $\mathrm{Al}^{3+}$ compared to $\mathrm{Fe}^{3+}$ could be due to several facts. Firstly, the water solubility of $\mathrm{FeF}_{3}$ is reported to be higher $\left(495 \mathrm{~g} / \mathrm{L}\right.$ at $\left.20^{\circ} \mathrm{c}\right)$ with respect to $\mathrm{AlF}_{3}\left(6.7 \mathrm{~g} / \mathrm{L}\right.$ at $\left.20^{\circ} \mathrm{c}\right)$. Additionally, we have calculated the formation energies of $\mathrm{AlF}_{3}(-115.19 \mathrm{~kJ} / \mathrm{mol})$ and $\mathrm{FeF}_{3}(-0.289 \mathrm{~kJ} / \mathrm{mol})$ in ethanol medium (as shown in Table $\mathrm{S} 1$ ) which suggest that the stability of $\mathrm{AlF}_{3}$ is much higher than $\mathrm{FeF}_{3}$ in the medium. Therefore, in the solution phase, fluoride ions could be easily separated out from $\mathrm{Fe}^{3+}$ compared to $\mathrm{Al}^{3+}$, which thereby participates in the substitution reaction with AlPc-Cl molecules. Therefore, higher interference of aluminium could be attributed to the lesser solubility and higher stability of the aluminium fluoride compounds. Moreover, it has been further observed that the sensitivity of the sensor at higher concentration of $\mathrm{Al}^{3+}$ and $\mathrm{Fe}^{3+}$ could be improved by increasing temperature upto $60^{\circ} \mathrm{C}$. This improvement in sensitivity at higher temperature is expected due to increase in solubility and dissociation possibility of iron and aluminium compounds which eventually increases the free fluoride concentration in the medium. ${ }^{50}$

\subsection{Development of a Prototype Device:}

In order to monitor the infield fluoride contamination, a cost effective as well as portable device is very much required. In this regard, we have developed a highly sensitive and 
portable prototype device based on the "turn-off" fluorescence mechanism. As shown in figure $8 \mathrm{a}$, the prototype device consists of a customized cuvette holder, a light source and a detector. Here, a $633 \mathrm{~nm}$ laser has been used as a light source and a CMOS (Complementary Metal Oxide Semiconductor) camera has been used as a detector. The laser and camera have been placed perpendicular to each other. A $650 \mathrm{~nm}$ band-pass filter (not shown in the figure) has been used to block the excitation light. The pixel intensity of the fluorescence snapshots obtained from the sensor with different concentrations of $\mathrm{F}^{-}$have been further analysed by an indigenously developed software using LabVIEW platform. $^{51}$ Fluorescence snapshots obtained from sensor in the absence $(0 \mathrm{ppm})$ and presence of $\mathrm{F}^{-}(3 \mathrm{ppm})$ have been shown in figure $8 \mathrm{~b}$. The decrease in fluorescence intensity can be distinctly observed from the images. The relative pixel intensity $\left(\mathrm{P}_{0} / \mathrm{P}\right)$ obtained from the fluorescence snapshot of the sensor with different concentrations of $\mathrm{F}^{-}$has been plotted in figure $8 \mathrm{c}$. The plot exhibits an excellent linear behaviour $\left(\mathrm{R}^{2}=0.986\right)$ for the fluoride concentration of 0 to $3 \mathrm{ppm}$. Furthermore, the LOD value is calculated to be $0.10 \mathrm{ppm}$ which is well below the WHO recommended limit of $1.5 \mathrm{ppm}$. Therefore, our prototype device meets all the required criteria for the detection of fluoride level in drinking water. We expect, this indigenously developed prototype device will provide an easy solution to the quantitative detection of fluoride concentration in remote areas where frequent monitoring of fluoride level in water is highly required.

\section{Conclusion:}

In summary, we have developed a facile, cost effective, highly sensitive and selective method for the determination of $\mathrm{F}^{-}$concentration in aqueous media by using $\mathrm{AlPc}-\mathrm{Cl}$ as sensor. The mechanism is based on the quenching in absorbance as well fluorescence intensity of AlPc-Cl in the presence of $\mathrm{F}^{-}$. The structural change in the sensor after addition of $\mathrm{F}^{-}$has been confirmed by using ${ }^{19} \mathrm{~F}$ NMR spectroscopy. It has been observed that the substitution of $\mathrm{Cl}^{-}$ by $\mathrm{F}^{-}$and subsequent formation of AlPc-F, having polymeric chain-like structure is 
responsible for the change in optical properties of the sensor. The mechanism of quenching has been thoroughly studied by using well-known Stern-Volmer plot which demonstrates that the quenching is static in nature due to the formation of non-emissive complex. Moreover, the sensor shows an excellent linear calibration curve for a wide concentration range of $\mathrm{F}^{-}(0-6$ ppm) as well as a low LOD of $0.05 \mathrm{ppm}$ which makes it a useful candidate for practical application purposes. Selectivity studies further reveal an insignificant response of the sensor towards other cations and anions, confirming its efficacy for selective detection of $\mathrm{F}^{-}$in water. Additionally, it shows high sensitivity even in the presence of interfering iron and aluminium ions. In the present study, we have also developed a portable prototype device based on the "turn-off" fluorescence mechanism. The device has shown excellent sensitivity towards fast detection of $\mathrm{F}^{-}$in aqueous media.

\section{Acknowledgements:}

A.C and T.K.M would like to thank DST-INSPIRE for fellowship. We thank DST, India for Abdul Kalam Technology Innovation National Fellowship (INAE/121/AKF). SK.SP thanks the CSIR, New Delhi, for providing CSIR-RA fellowship.

\section{Conflict of Interest:}

Authors declare no conflict of interest. 


\section{References:}

1. Sarkar, P. K.; Kar, P.; Halder, A.; Lemmens, P.; Pal, S. K., Development of Highly Efficient Dual Sensor Based on Carbon Dots for Direct Estimation of Iron and Fluoride Ions in Drinking Water. ChemistrySelect 2019, 4 (15), 4462-4471.

2. McDonagh, C.; Burke, C. S.; MacCraith, B. D., Optical chemical sensors. Chemical reviews 2008, 108 (2), 400-422.

3. Stich, M. I.; Fischer, L. H.; Wolfbeis, O. S., Multiple fluorescent chemical sensing and imaging. Chemical Society Reviews 2010, 39 (8), 3102-3114.

4. Li, L.; Ji, Y.; Tang, X., Quaternary ammonium promoted ultra selective and sensitive fluorescence detection of fluoride ion in water and living cells. Analytical chemistry 2014, 86 (20), 10006-10009.

5. Kim, T. H.; Swager, T. M., A fluorescent self-amplifying wavelength-responsive sensory polymer for fluoride ions. Angewandte Chemie International Edition 2003, 42 (39), 4803-4806.

6. Gopal, R.; Ghosh, P., Fluoride in drinking water-its effects and removal. Def Sci J $1985,35(1), 71-88$.

7. Health, U. D. o.; Fluoridation, H. S. F. P. o. C. W., US Public Health Service recommendation for fluoride concentration in drinking water for the prevention of dental caries. Public Health Reports 2015, 130 (4), 318-331.

8. Yadav, K. K.; Kumar, S.; Pham, Q. B.; Gupta, N.; Rezania, S.; Kamyab, H.; Yadav, S.; Vymazal, J.; Kumar, V.; Tri, D. Q., Fluoride contamination, health problems and remediation methods in Asian groundwater: A comprehensive review. Ecotoxicology and environmental safety 2019, 182, 109362. 
9. Sahu, B. L.; Banjare, G. R.; Ramteke, S.; Patel, K. S.; Matini, L., Fluoride contamination of groundwater and toxicities in dongargaon block, Chhattisgarh, India. Exposure and Health 2017, 9 (2), 143-156.

10. Guth, S.; Hüser, S.; Roth, A.; Degen, G.; Diel, P.; Edlund, K.; Eisenbrand, G.; Engel, K.-H.; Epe, B.; Grune, T., Toxicity of fluoride: critical evaluation of evidence for human developmental neurotoxicity in epidemiological studies, animal experiments and in vitro analyses. Archives of toxicology 2020, 94 (5), 1375-1415.

11. Lu, Y.; Sun, Z.; Wu, L.; Wang, X.; Lu, W.; Liu, S., Effect of high-fluoride water on intelligence in children. Fluoride 2000, 33 (2), 74-78.

12. Naha, S.; Velmathi, S., Phenazine-Based Fluorescence "Turn-Off” Sensor for Fluoride: Application on Real Samples and to Cell and Zebrafish Imaging. ChemistrySelect 2019, 4 (10), 2912-2917.

13. Martinez-Mier, E. A.; Cury, J. A.; Heilman, J. R.; Katz, B.; Levy, S.; Li, Y.; Maguire, A.; Margineda, J.; O’Mullane, D.; Phantumvanit, P., Development of gold standard ion-selective electrode-based methods for fluoride analysis. Caries research 2011, $45(1), 3-12$.

14. Hang, Y.-P.; Liu, J.-M., Determination of fluoride by an ion chromatography system using the preconcentration on nanometer-size zirconia. Journal of Analytical Chemistry 2007, $62(6), 583-587$.

15. Moens, L.; Verrept, P.; Dams, R.; Greb, U.; Jung, G.; Laser, B., New highresolution inductively coupled plasma mass spectrometry technology applied for the determination of $\mathrm{V}, \mathrm{Fe}, \mathrm{Cu}, \mathrm{Zn}$ and $\mathrm{Ag}$ in human serum. Journal of analytical atomic spectrometry 1994, 9 (9), 1075-1078.

16. L'vov, B., Fifty years of atomic absorption spectrometry. Journal of Analytical Chemistry 2005, 60 (4), 382-392. 
17. Moerner, W. E.; Kador, L., Optical detection and spectroscopy of single molecules in a solid. Physical review letters 1989, 62 (21), 2535.

18. Boiocchi, M.; Del Boca, L.; Gómez, D. E.; Fabbrizzi, L.; Licchelli, M.; Monzani, E., Nature of urea- fluoride interaction: incipient and definitive proton transfer. Journal of the American Chemical Society 2004, 126 (50), 16507-16514.

19. Melaimi, M.; Gabbaï, F. P., A heteronuclear bidentate Lewis acid as a phosphorescent fluoride sensor. Journal of the American Chemical Society 2005, 127 (27), 9680-9681.

20. Farinha, A. S.; Fernandes, M. R.; Tomé, A. C., Chromogenic anion molecular probes based on $\beta$, $\beta$ '-disubstituted calix [4] pyrroles. Sensors and Actuators B: Chemical 2014, 200, $332-338$.

21. Moser, F.; Thomas, A., Phthalocyanine Compounds., Reinhold Publ. Co. New York, Chapman and Hall, London: 1963.

22. Moser, F.; Thomas, A., Phthalocyanine Compounds, Reinhold Pub. Co., New York 1963.

23. Williams, G.; Sutty, S.; Klenkler, R.; Aziz, H., Renewed interest in metal phthalocyanine donors for small molecule organic solar cells. Solar Energy Materials and Solar Cells 2014, 124, 217-226.

24. Seddigi, Z. S.; Ahmed, S. A.; Sardar, S.; Pal, S. K., Ultrafast dynamics at the zinc phthalocyanine/zinc oxide nanohybrid interface for efficient solar light harvesting in the near red region. Solar Energy Materials and Solar Cells 2015, 143, 63-71.

25. Xu, D.; You, Y.; Zeng, F.; Wang, Y.; Liang, C.; Feng, H.; Ma, X., Disassembly of hydrophobic photosensitizer by biodegradable zeolitic imidazolate framework- 8 for photodynamic cancer therapy. ACS applied materials \& interfaces 2018, 10 (18), 1551715523. 
26. Managa, M.; Idowu, M. A.; Antunes, E.; Nyokong, T., Photophysicochemical behavior and antimicrobial activity of dihydroxosilicon tris (diaquaplatinum) octacarboxyphthalocyanine. Spectrochimica Acta Part A: Molecular and Biomolecular Spectroscopy 2014, 125, 147-153.

27. Klyamer, D. D.; Sukhikh, A. S.; Krasnov, P. O.; Gromilov, S. A.; Morozova, N. B.; Basova, T. V., Thin films of tetrafluorosubstituted cobalt phthalocyanine: Structure and sensor properties. Applied Surface Science 2016, 372, 79-86.

28. Jiang, Z.; Yang, T.; Liu, M.; Hu, Y.; Wang, J., An aptamer-based biosensor for sensitive thrombin detection with phthalocyanine@ $\mathrm{SiO} 2$ mesoporous nanoparticles. Biosensors and Bioelectronics 2014, 53, 340-345.

29. Kaya, E. N.; Şenocak, A.; Klyamer, D. D.; Demirbaş, E.; Basova, T. V.; Durmuş, M., Ammonia sensing performance of thin films of cobalt (II) phthalocyanine bearing fluorinated substituents. Journal of Materials Science: Materials in Electronics 2019, 30 (8), 7543-7551.

30. Çeken, B.; Kandaz, M.; Koca, A., Electrochemical metal-ion sensors based on a novel manganese phthalocyanine complex. Synthetic metals 2012, 162 (17-18), 1524-1530.

31. Lessard, B. H.; Mohammad, A.-A.; Grant, T. M.; White, R.; Lu, Z.-H.; Bender, T. P., From chloro to fluoro, expanding the role of aluminum phthalocyanine in organic photovoltaic devices. Journal of Materials Chemistry A 2015, 3 (9), 5047-5053.

32. Muehlmann, L. A.; Rodrigues, M. C.; Longo, J. P. F.; Garcia, M. P.; Py-Daniel, K. R.; Veloso, A. B.; de Souza, P. E. N.; da Silva, S. W.; Azevedo, R. B., Aluminiumphthalocyanine chloride nanoemulsions for anticancer photodynamic therapy: Development and in vitro activity against monolayers and spheroids of human mammary adenocarcinoma MCF-7 cells. Journal of nanobiotechnology 2015, 13 (1), 36. 
33. Nohr, R. S.; Kuznesof, P. M.; Wynne, K. J.; Kenney, M. E.; Siebenman, P., Highly conducting linear stacked polymers: iodine-doped fluoroaluminum and fluorogallium phthalocyanines. Journal of the American Chemical Society 1981, 103 (15), 4371-4377.

34. Linsky, J. P.; Paul, T. R.; Nohr, R. S.; Kenney, M. E., Studies of a series of haloaluminum,-gallium, and-indium phthalocyanines. Inorganic Chemistry 1980, 19 (10), $3131-3135$.

35. Sarkar, P. K.; Halder, A.; Polley, N.; Pal, S. K., Development of highly selective and efficient prototype sensor for potential application in environmental mercury pollution monitoring. Water, Air, \& Soil Pollution 2017, 228 (8), 314.

36. Sardar, S.; Kar, P.; Sarkar, S.; Lemmens, P.; Pal, S., Interfacial carrier dynamics in $\mathrm{PbS}-\mathrm{ZnO}$ light harvesting assemblies and their potential implication in photovoltaic/photocatalysis application. Solar Energy Materials and Solar Cells 2015, 134, 400-406.

37. Vilsinski, B. H.; Gerola, A. P.; Lemos, É. O.; Barbosa, P. M.; Campanholi, K. S.; César, G. B.; Hioka, N.; Caetano, W., Spectroscopic study of aluminum phthalocyanine chloride $(\mathrm{AlPcCl})$ in homogeneous and micro-heterogeneous media consisting of P-123 and F-127 polymeric micelles. Química Nova 2015, 38 (5), 631-639.

38. Djurado, D.; Fabre, C.; Hamwi, A.; Cousseins, J., High resolution solid-state 13C CPMAS study of neutral and partially oxidized aluminium polyfluorophthalocyanines. Synthetic metals 1987, 22 (2), 121-128.

39. Hudlicky, M., Chemical shifts of fluorine in hydrogen fluoride and fluoride ion. Journal of fluorine chemistry 1985, 28 (4), 461-472.

40. Bayda, M.; Dumoulin, F.; Hug, G. L.; Koput, J.; Gorniak, R.; Wojcik, A., Fluorescent $\mathrm{H}$-aggregates of an asymmetrically substituted mono-amino $\mathrm{Zn}$ (II) phthalocyanine. Dalton transactions 2017, 46 (6), 1914-1926. 
41. Adhikari, A.; Darbar, S.; Chatterjee, T.; Das, M.; Polley, N.; Bhattacharyya, M.; Bhattacharya, S.; Pal, D.; Pal, S. K., Spectroscopic studies on dual role of natural flavonoids in detoxification of lead poisoning: Bench-to-bedside preclinical trial. ACS omega 2018, 3 (11), 15975-15987.

42. Schibilla, F.; Stegemann, L.; Strassert, C. A.; Rizzo, F.; Ravoo, B. J., Fluorescence quenching in $\beta$-cyclodextrin vesicles: membrane confinement and host-guest interactions. Photochemical \& Photobiological Sciences 2016, 15 (2), 235-243.

43. Rodríguez-Cáceres, M.; Agbaria, R.; Warner, I., Fluorescence of metal-ligand complexes of mono-and di-substituted naphthalene derivatives. Journal of fluorescence 2005, $15(2), 185-190$.

44. Halder, A.; Singh, S.; Adhikari, A.; Singh, P.; Sarkar, P. K.; Pal, U.; Ghosh, R.; Shikha, D.; Solanki, Y. S.; Agarwal, M., Selective and fast responsive sensitized micelle for detection of fluoride level in drinking water. ACS Sustainable Chemistry \& Engineering 2019, 7 (19), 16355-16363.

45. Zhou, Y.; Dong, X.; Zhang, Y.; Tong, P.; Qu, J., Highly selective fluorescence sensors for the fluoride anion based on carboxylate-bridged diiron complexes. Dalton Transactions 2016, 45 (16), 6839-6846.

46. Yeh, J.-T.; Venkatesan, P.; Wu, S.-P., A highly selective turn-on fluorescent sensor for fluoride and its application in imaging of living cells. New Journal of Chemistry 2014, 38 (12), 6198-6204.

47. Singh, P.; Prabhune, A. A.; Tripathi, C. S. P.; Guin, D., Water-soluble photoluminescence on-off-on probe for speedy and selective detection of fluoride ions. ACS Sustainable Chemistry \& Engineering 2017, 5 (1), 982-987. 
48. Nwaichi, E.; Wegwu, M.; Nwosu, U., Distribution of selected carcinogenic hydrocarbon and heavy metals in an oil-polluted agriculture zone. Environmental Monitoring and Assessment 2014, 186 (12), 8697-8706.

49. See, W. P.; Heng, L. Y.; Nathan, S., Highly sensitive aluminium (III) ion sensor based on a self-assembled monolayer on a gold nanoparticles modified screen-printed carbon electrode. Analytical Sciences 2015, 31 (10), 997-1003.

50. Tjus, K.; Bergstrom, R.; Fortkamp, U.; Forsberg, K.; Rasmuson, A., Development of a Recovery System for Metals and Acids from Pickling Baths using Nanofiltration and Crystallisation. SWEDISH WATER AND AIR POLLUTION RESEARCH LABORATORYPUBLICATIONS-IVL B 2007, 1692.

51. Singh, S.; Halder, A.; Sinha, O.; Chakrabarty, N.; Chatterjee, T.; Adhikari, A.; Singh, P.; Shikha, D.; Ghosh, R.; Banerjee, A., Spectroscopic Studies on the Biomolecular Recognition of Toluidine Blue: Key Information Towards Development of a Non-Contact, Non-Invasive Device for Oral Cancer Detection. Frontiers in Oncology 2020, 10, 2293. 

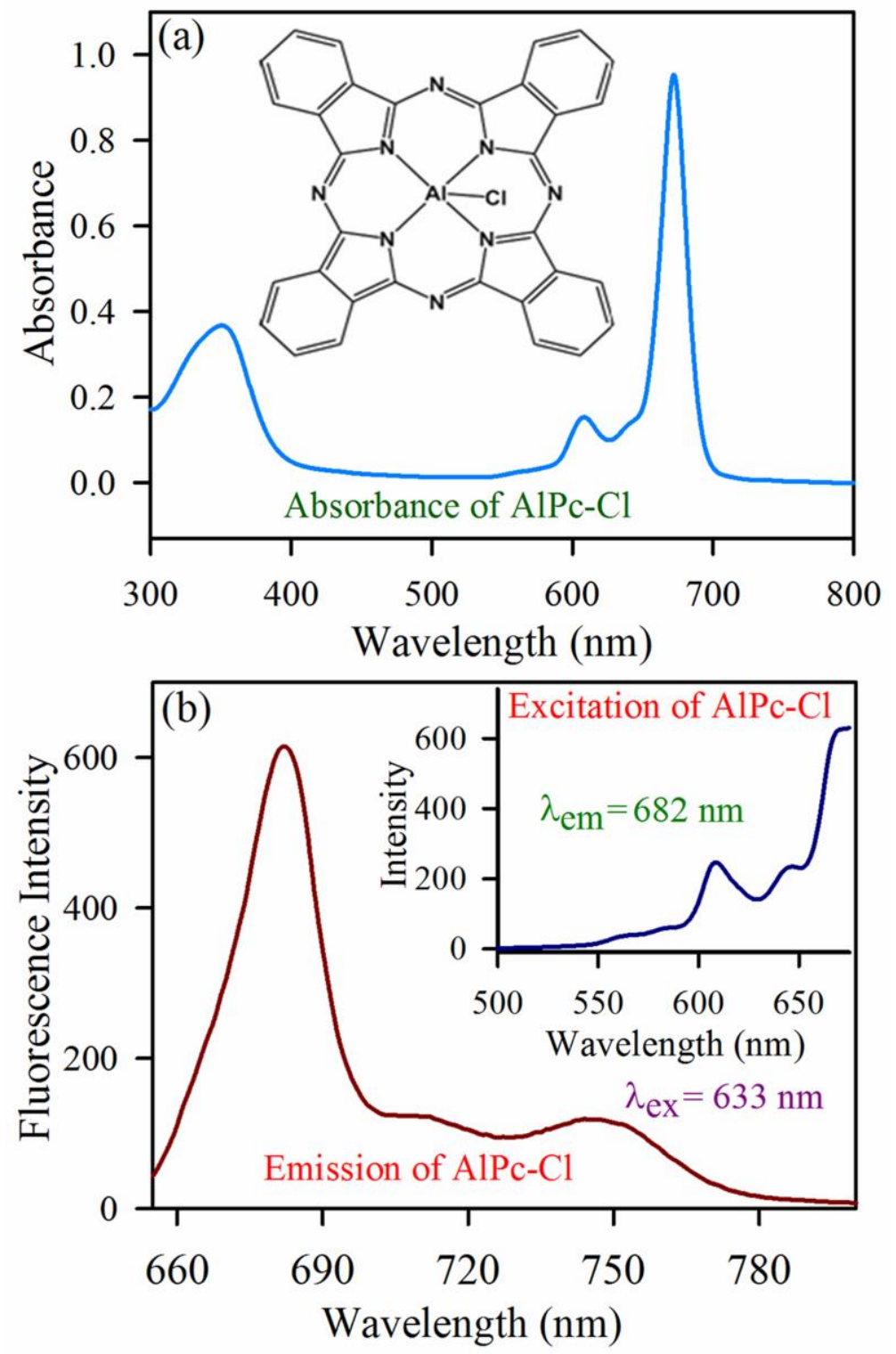

Figure 1. (a) Absorbance spectrum of AlPc-Cl. Inset shows the molecular structure of AlPcCl. (b) Steady-state fluorescence spectrum of AlPc-Cl upon excitation at $633 \mathrm{~nm}$. Inset shows the excitation spectrum of AlPc-Cl $\left(\lambda_{\mathrm{em}}=682 \mathrm{~nm}\right)$. 

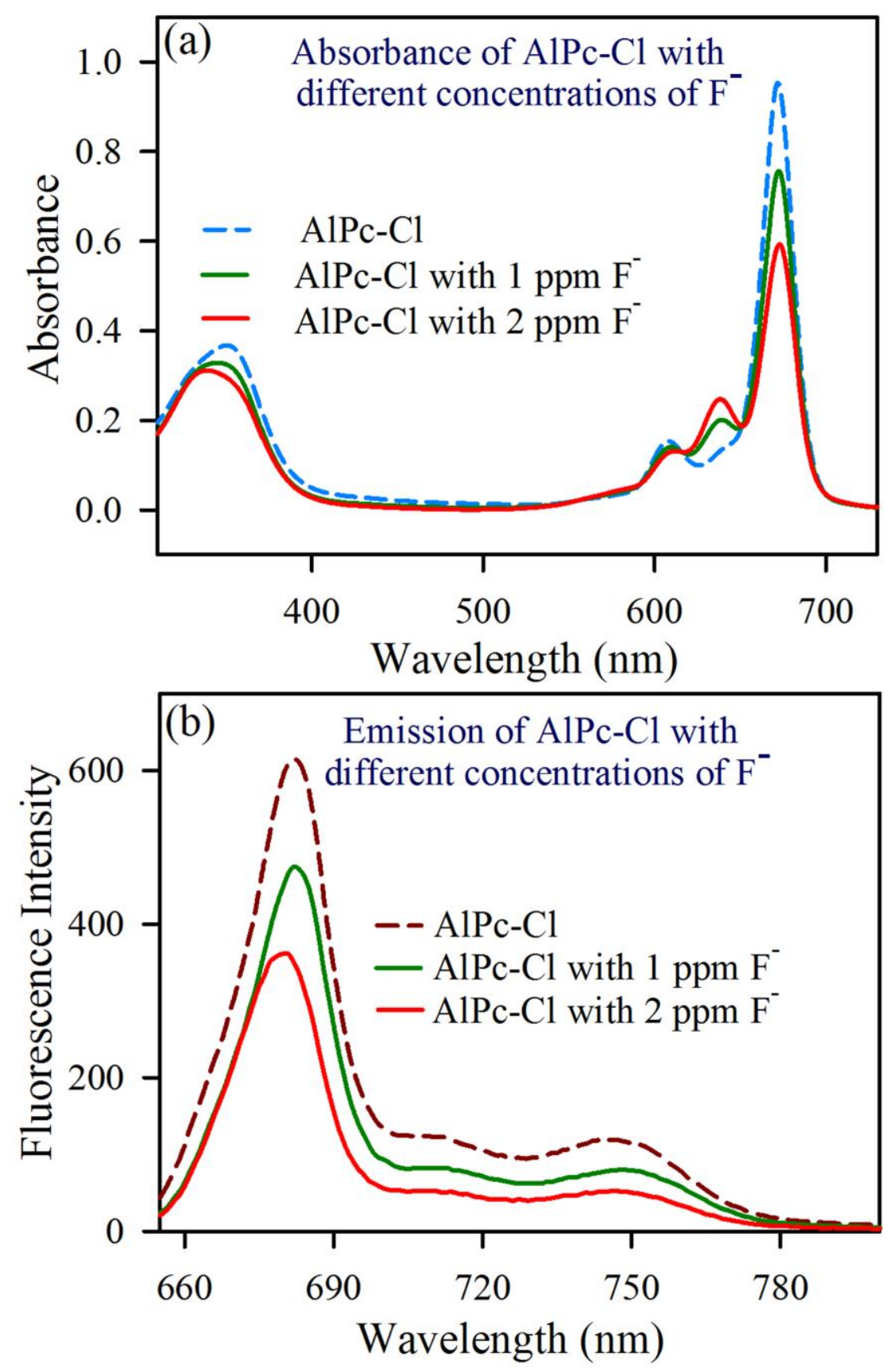

Figure 2. (a) Absorbance and (b) Steady state fluorescence spectra $\left(\lambda_{\mathrm{ex}}=633 \mathrm{~nm}\right)$ of $\mathrm{AlPc}-\mathrm{Cl}$ in the presence of $1 \mathrm{ppm}$ (dark green) and $2 \mathrm{ppm}$ (red) of $\mathrm{F}^{-}$. 

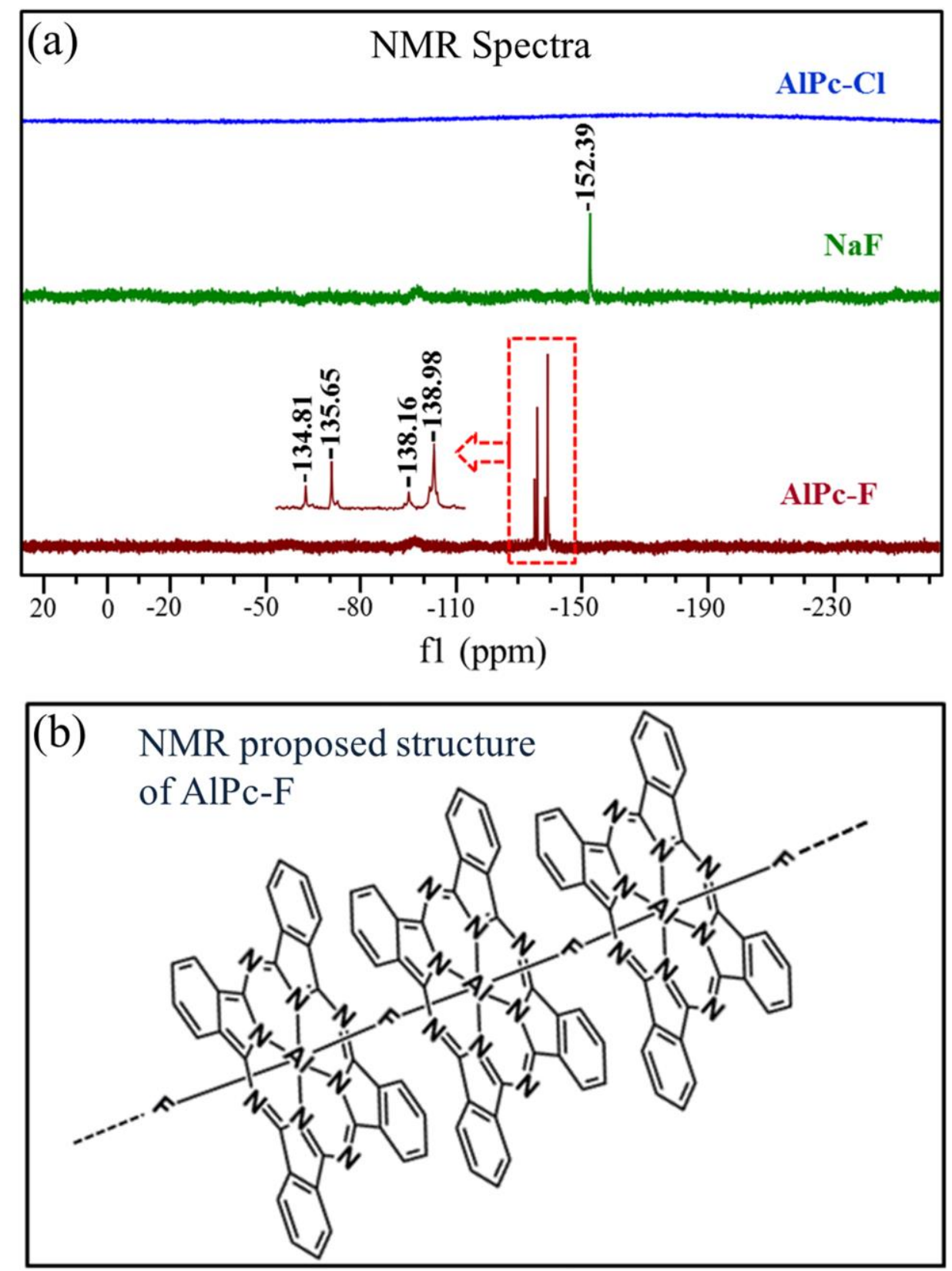

Figure 3. (a) ${ }^{19} \mathrm{~F}$ NMR spectra of AlPc-Cl, $\mathrm{NaF}$ and AlPc-F. Inset shows the magnified NMR peaks of AlPc-F. (b) NMR proposed structure of AlPc-F. 

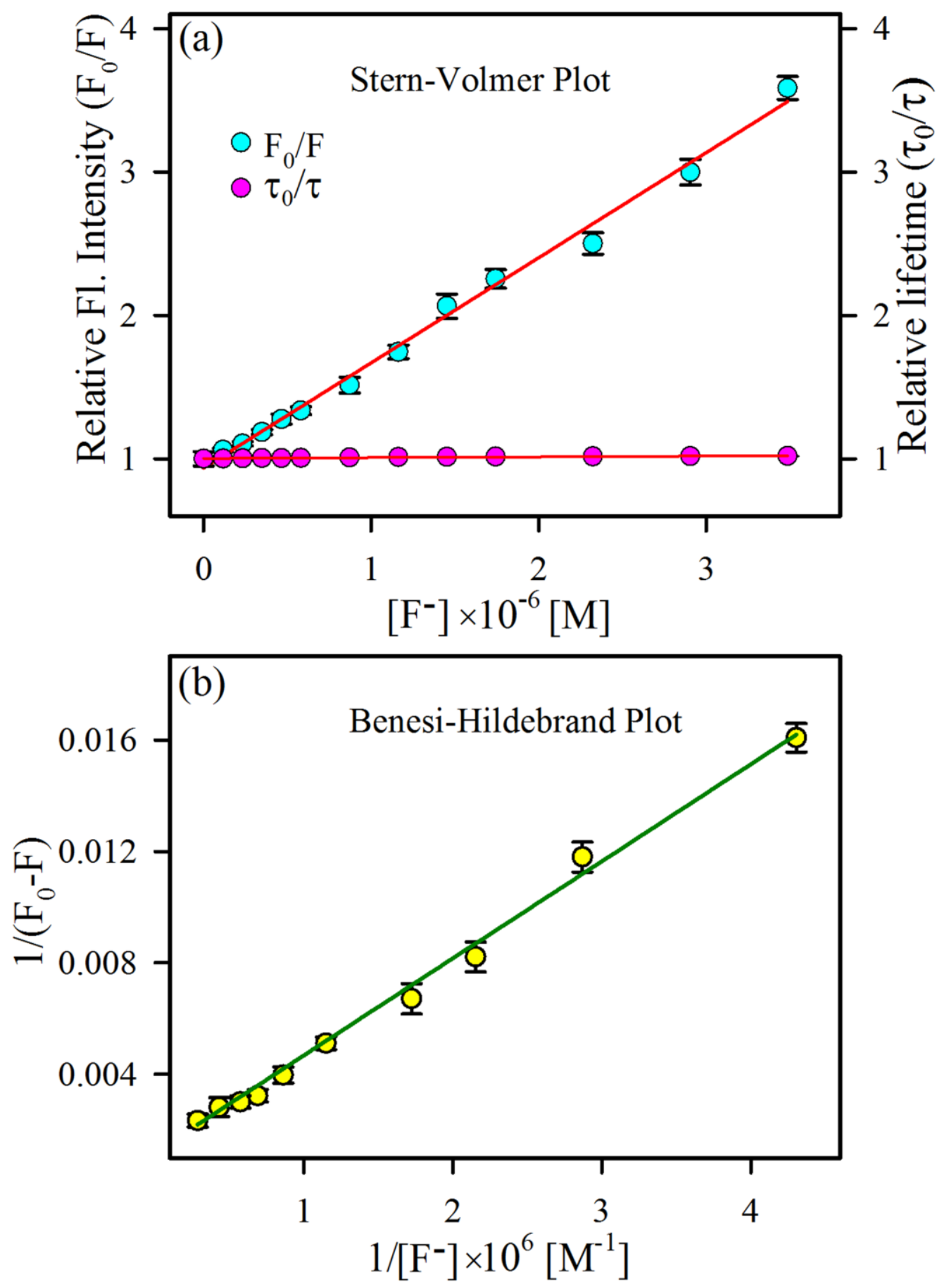

Figure 4. (a) Plots of $\mathrm{F}_{0} / \mathrm{F}$ vs $\left[\mathrm{F}^{-}\right]$(blue) and $\tau_{0} / \tau$ vs $\left[\mathrm{F}^{-}\right]$(pink). (b) BenesiHildebrand plot of $1 /\left[\mathrm{F}_{0}-\mathrm{F}\right]$ vs $1 /\left[\mathrm{F}^{-}\right]$. Here, fluorescence intensity has been monitored at $682 \mathrm{~nm}$. 

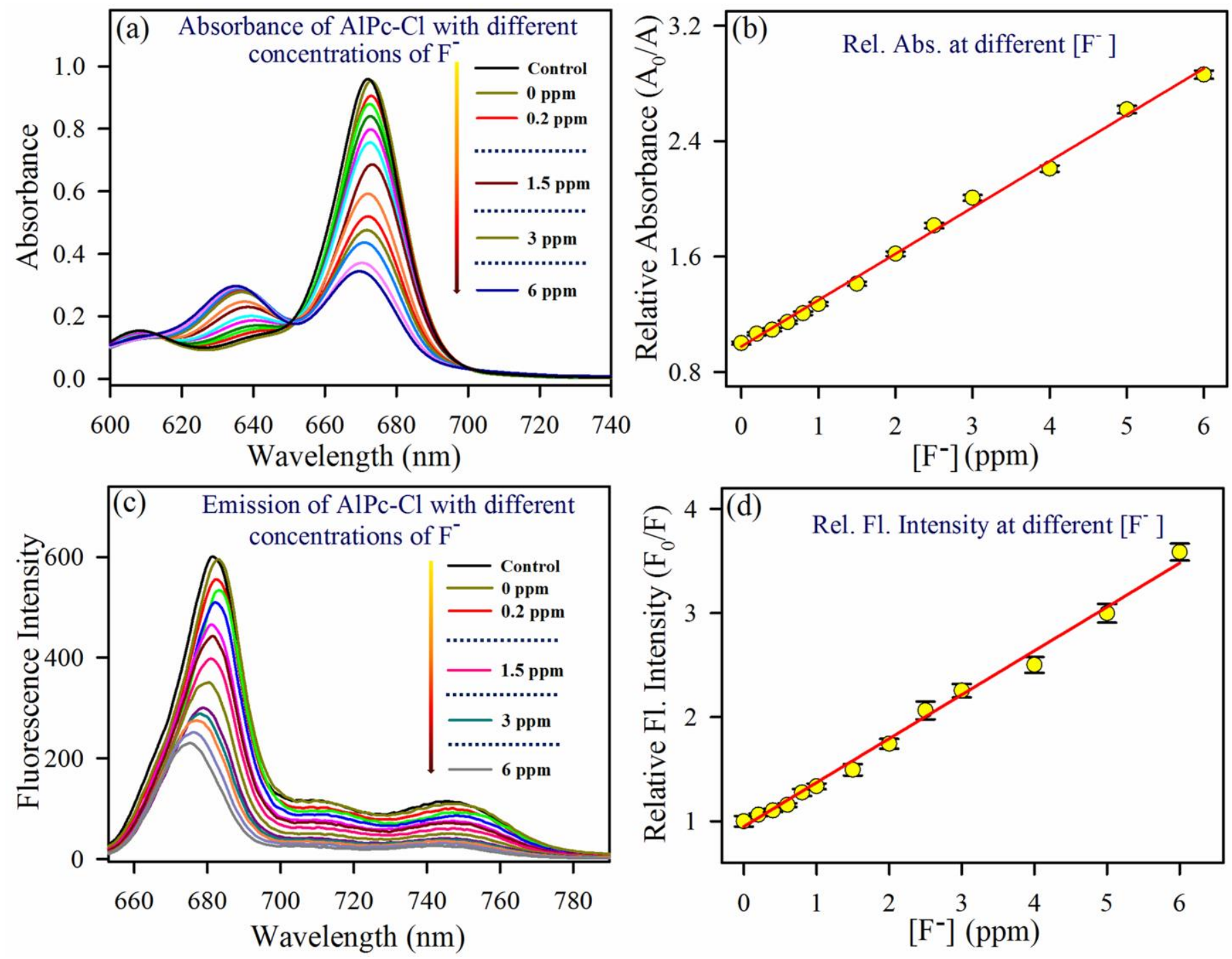

Figure 5. (a) Absorbance spectra of AlPc-Cl upon addition of $\mathrm{F}^{-}$ions (0-6 ppm). (b) The plot of relative absorbance $\left(\mathrm{A}_{0} / \mathrm{A}\right)$ vs $\left[\mathrm{F}^{-}\right]$, monitored at $672 \mathrm{~nm}$. (c) Steady-state fluorescence spectra $\left(\lambda_{\mathrm{ex}}=633 \mathrm{~nm}\right)$ of AlPc-Cl with increasing concentration of $\mathrm{F}^{-}(0-6 \mathrm{ppm})$, monitored at $682 \mathrm{~nm}$. (d) The plot of relative fluorescence intensity $\left(\mathrm{F}_{0} / \mathrm{F}\right)$ vs $\left[\mathrm{F}^{-}\right]$, monitored at $682 \mathrm{~nm}$. 

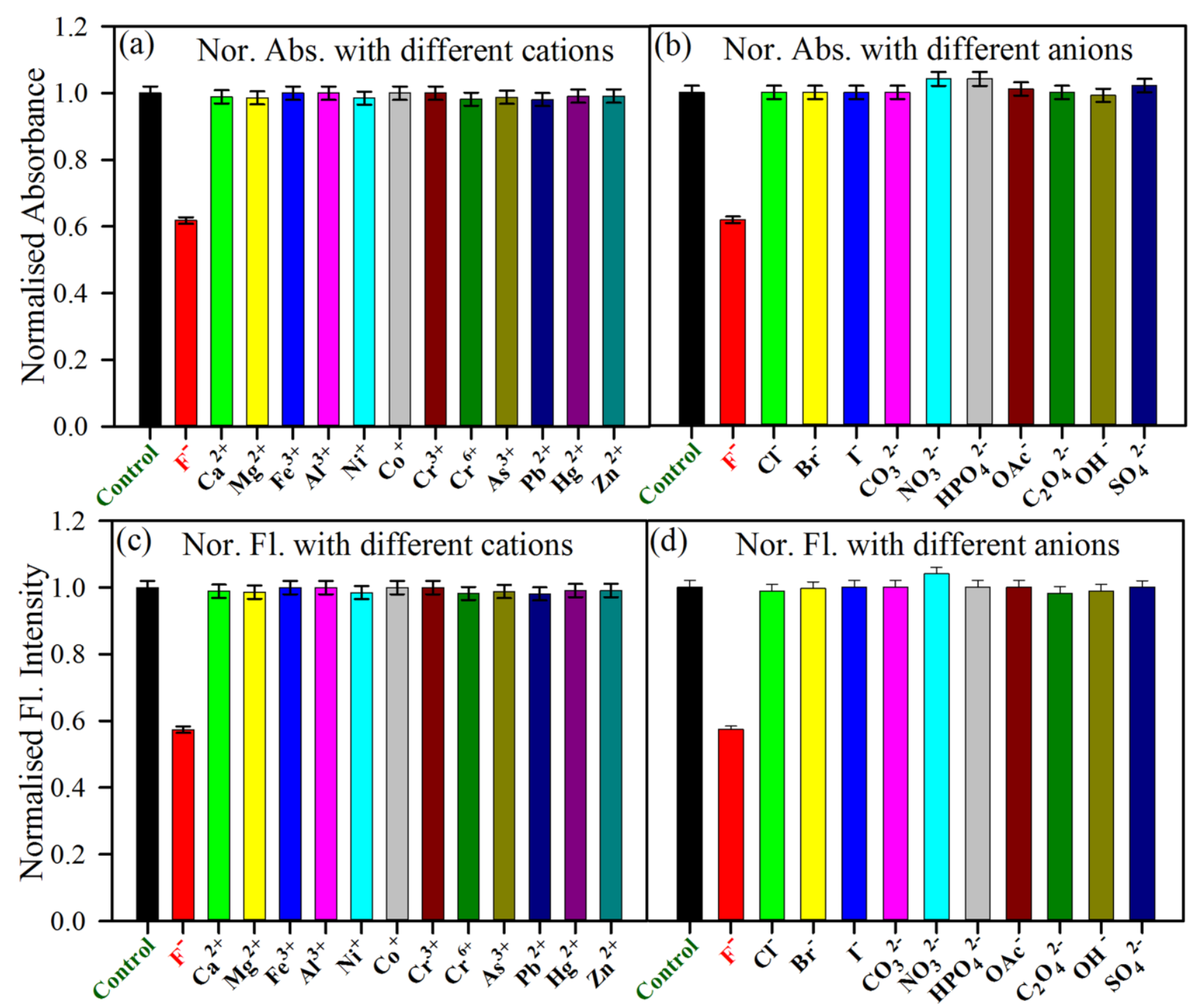

Figure 6. Normalised absorbance of the sensor (AlPc-Cl) in the presence of different (a) cations and (b) anions, monitored at $672 \mathrm{~nm}$. Normalised fluorescence intensity $\left(\lambda_{\mathrm{ex}}=633\right.$ $\mathrm{nm}$ ) of the sensor in the presence of different (c) cations and (d) anions, monitored at 682 $\mathrm{nm}$. Note the concentration of each and every ions including $\mathrm{F}^{-}$has been kept same (2 nom). 

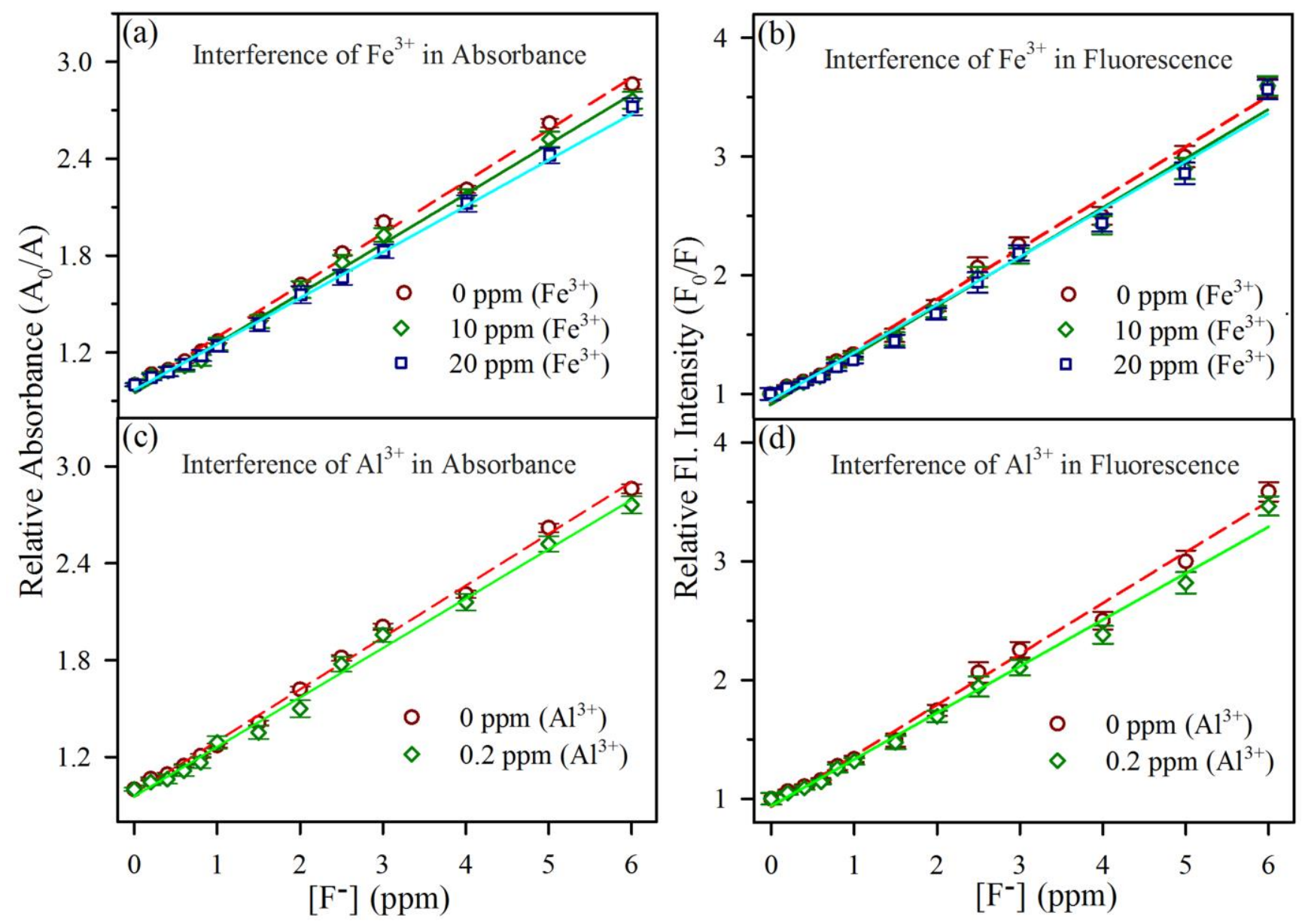

Figure 7. The plot of (a) relative absorbance $\left(\mathrm{A}_{0} / \mathrm{A}\right)$ and $(\mathrm{b})$ relative fluorescence intensity $\left(\mathrm{F}_{0} / \mathrm{F}\right)$ vs $\left[\mathrm{F}^{-}\right]$in the presence of 10 and $20 \mathrm{ppm}$ of $\mathrm{Fe}^{3+}$. (c) and (d) show the plot of $\left(\mathrm{A}_{0} / \mathrm{A}\right)$ and $\left(\mathrm{F}_{0} / \mathrm{F}\right)$ vs $\left[\mathrm{F}^{-}\right]$respectively in the presence of $0.2 \mathrm{ppm} \mathrm{Al}^{3+}$. 

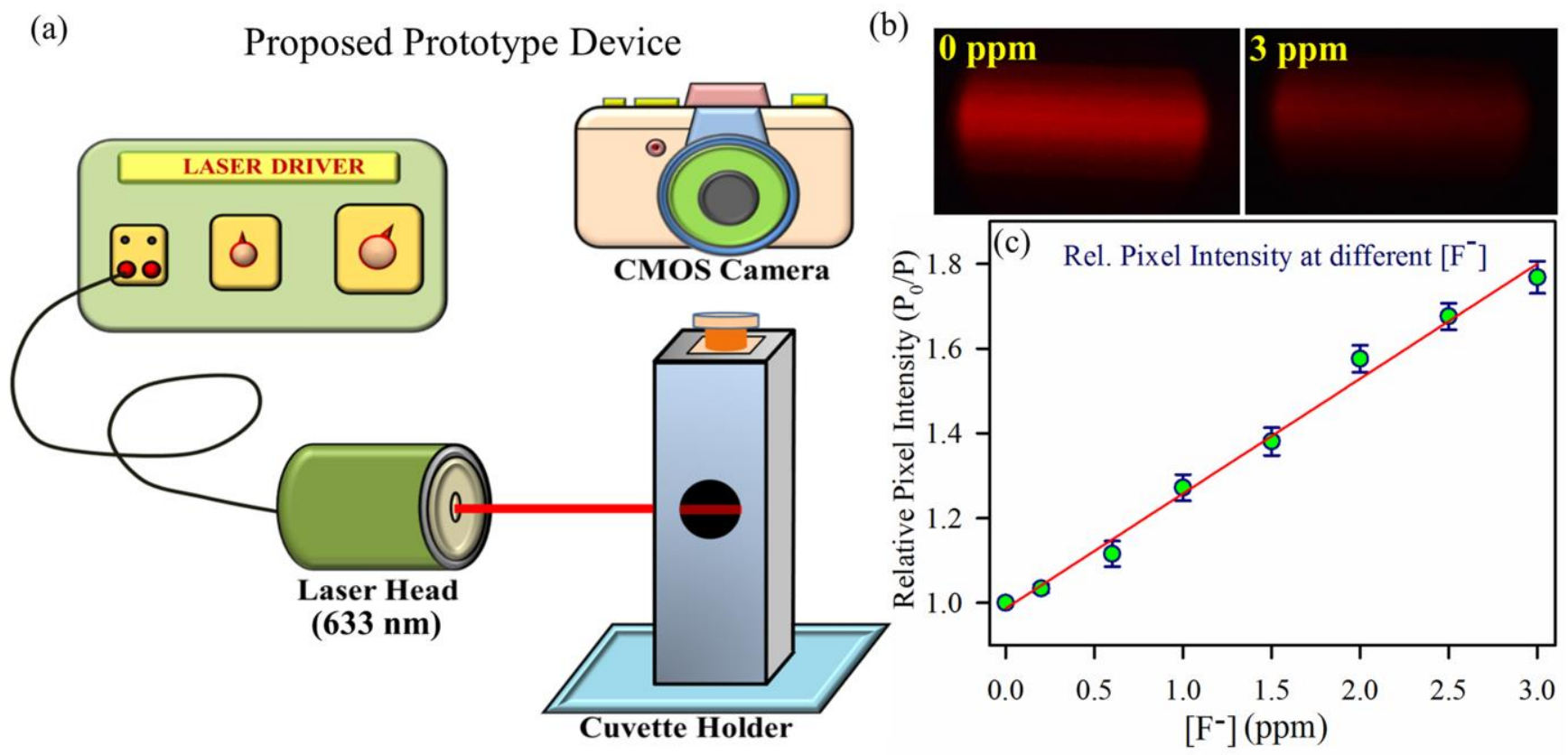

Figure 8. (a) Schematic of proposed prototype device for the sensing of fluoride in water. (b) Fluorescence snapshots of the sensor in the presence of 0 and $3 \mathrm{ppm}$ of $\mathrm{F}^{-}$. (c) Calibration curve obtained from the prototype device for the fluoride concentration of 0 to $3.0 \mathrm{ppm}$. 


\section{Table of Content}

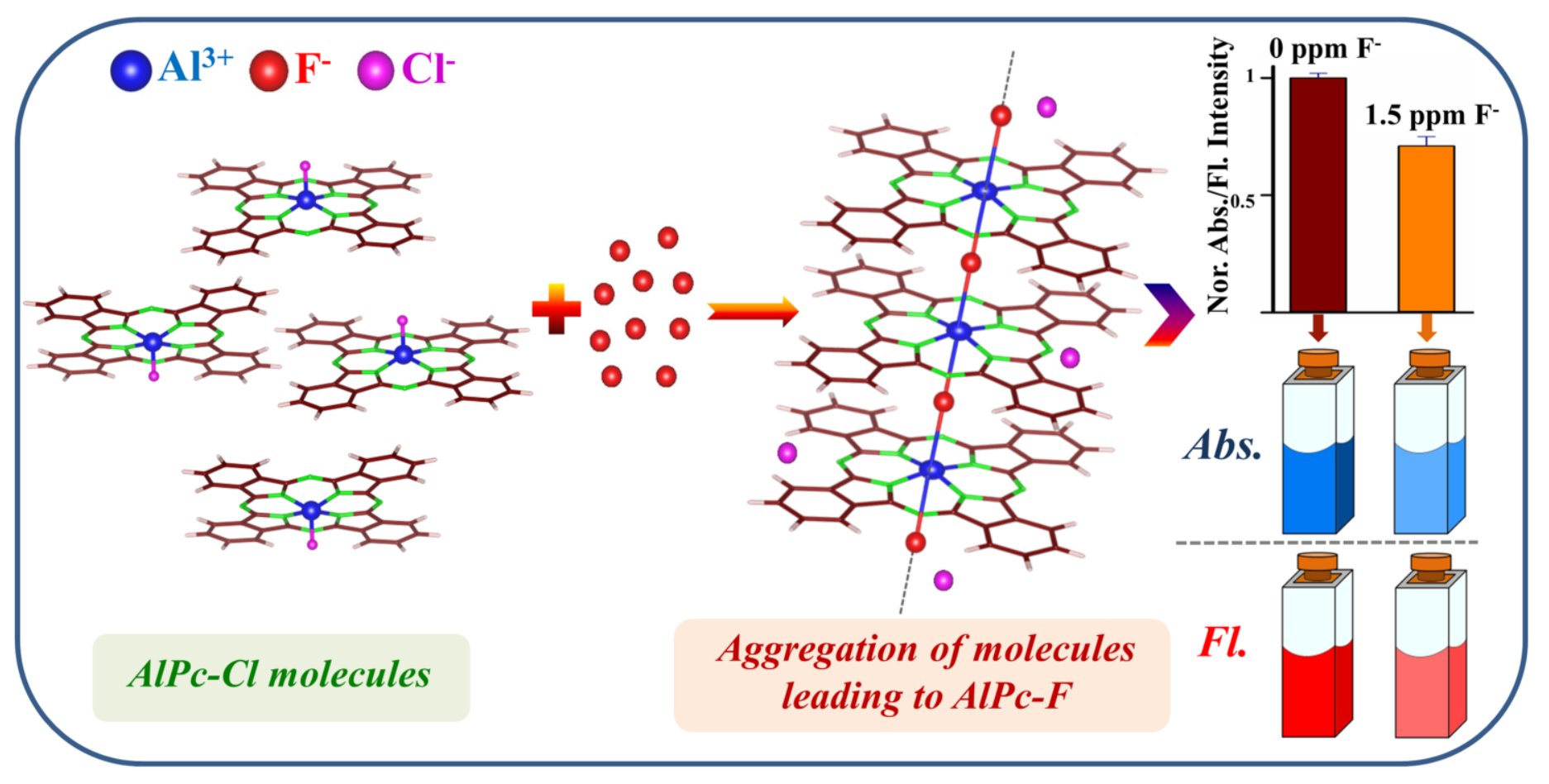

